\title{
AVALIAÇÃO E QUANTIFICAÇÃO DO TEOR DE FENÓIS DAS PARTES DA Morinda citrifolia Linn (Noni)
}

\author{
(*) RÊGO ${ }^{1}$, F. E. (IFRN), BERTINI' ${ }^{2}$ L. M. (IFRN) ALVES ${ }^{3}$, L. A. (IFRN) \\ E-mail: emerianei@hotmail.com ${ }^{1}$; luciana.bertini@ifrn.edu.br ${ }^{2}$; leonardo.alcantara@ifrn.edu.br ${ }^{3}$
}

\section{RESUMO}

Desde os tempos mais antigos a população utiliza medicamentos produzidos a partir da natureza, isso devido a grande diversidade de espécies vegetais presente no Brasil. Na atualidade esse uso vem crescendo, e trazendo benefícios a população que procura nesses produtos uma alternativa de cura ou prevenção de doenças. Dentre as várias espécies vegetais utilizadas para fins medicinais, a Morinda citrifolia Linn tem despertado interesse científico devido aos benefícios relacionados ao seu consumo.
Os extratos da Morinda citrifolia Linn, foram submetidos a testes para a quantificação do teor de fenóis totais pelo do método Folin-Ciocalteau em que se obteve um resultado satisfatório para a polpa e semente do fruto verde, em que apresentou os seguintes valores 181,0;160,0 mg EAG/g de extrato bruto, respectivamente. Observa-se que é importância o estudo dessa planta, pois apresenta poucos trabalhos na literatura e é uma espécie muito utilizada na medicina popular.

PALAVRAS-CHAVE: Produtos naturais, Morinda citrifolia Linn, Teor de fenóis

\section{EVALUATION AND MEASUREMENT OF PHENOLS CONTENT OF PIECES Morinda citrifolia Linn (Noni)}

\begin{abstract}
Since the earliest times the population uses drugs produced from nature, that due to the great diversity of plant species present in Brazil. Today this usage is growing, and bringing benefits to people seeking these products a healing alternative or prevention doenças.Dentre the various plant species used for medicinal purposes, Morinda citrifolia Linn has attracted scientific interest due to the benefits related to their consumption. Extracts of Morinda citrifolia Linn,
\end{abstract}

underwent tests to quantify the content of total phenols by the Folin-Ciocalteu method was obtained a satisfactory result for the pulp and seed green fruit, he presented the following values $181.0 ; 160.0 \mathrm{mg} \mathrm{GAE} / \mathrm{g}$ of crude extract, respectively. It is observed that it is important to study this plant, because it presents few studies in the literature and is very much used in folk medicine. 


\section{AVALIAÇÃO E QUANTIFICAÇÃO DO TEOR DE FENÓIS DAS PARTES DA Morinda citrifolia Linn (Noni)}

\section{INTRODUÇÃO}

No Brasil tem uma grande variedade de espécies vegetais que desde tempos mais antigos são utilizados para fins medicinais. Atualmente esse uso vem crescendo, e trazendo benefícios a população, comprovando que as espécies vegetais são ricas em substâncias que podem ajudar na saúde humana.

Morinda citrifolia Linn, conhecida popularmente por noni, espécie originada na Ásia e Polinésia. Na Polinésia é utilizada como antiviral, antifúngico, antitumoral, analgésico, anti-hipertensivo e antiinflamatório (KAMIYA, 2008).

Já foram identificados aproximadamente 160 compostos fitoquímicos da planta noni, sendo a maioria compostos fenólicos, ácidos orgânicos e alcalóides (HEINICKE, 1985). De acordo com Costa (2001), todas as partes do noni são aproveitadas, sendo o fruto a parte mais consumida devido ser rico em vitaminas, proteínas e minerais.

Nesse contexto, o presente trabalho teve como objetivo quantificar os teores totais de fenóis da Morinda citrifolia Linn (noni), por meio dos extratos etanólicos para o fruto verde e maduro desta espécie vegetal.

\section{MATERIAIS E MÉTODOS}

\subsection{Preparação dos Extratos}

O fruto (verde e maduro) da Morinda citrifolia foram coletados em um perímetro urbano do município de Apodi-RN. Os mesmos foram separados em polpa, casca e semente em que cada uma das partes foram trituradas e em seguida colocado em recipientes de vidro com etanol deixando em contato por 7 dias. Após esse período o solvente foi filtrado e concentrado em um rota evaporador, obtendo-se assim o extrato em etanol.

\subsection{Determinação do teor de fenóis totais pelo método de folin-ciocalteu}

Cada amostra vegetal foi dissolvida em metanol, e em seguida transferida para um balão volumétrico de $100 \mathrm{~mL}$ e aferido com metanol. Em outro balão, de $50 \mathrm{~mL}$, foram transferidos $7,5 \mathrm{~mL}$ da solução inicial, na qual esta segunda solução teve seu volume acertado com metanol. Uma alíquota de $100 \mu \mathrm{L}$ desta última solução foi agitada com 500 $\mu \mathrm{L}$ do reagente de Folin-Ciocalteu e $6 \mathrm{~mL}$ de água destilada por $1 \mathrm{~min}$. Após esse tempo foi adicionado $2 \mathrm{~mL}$ de carbonato de sódio $\left(\mathrm{Na}_{2} \mathrm{CO}_{3}\right) 15 \%$ a mistura e agitada por $30 \mathrm{~s}$. A solução teve seu volume acertado para $10 \mathrm{~mL}$ com água destilada. Após $2 \mathrm{~h}$ a absorbância das amostras foram medidas no espectrofotômetro de UV marca TEN-KA T-2000 no comprimento de onda de $750 \mathrm{~nm}$ (BONOLI et al., 2004). Os testes foram feitos em triplicata. Para determinação do teor de fenóis foi feita uma curva de calibração com padrões de ácido gálico (10 a $350 \mu \mathrm{g} / \mathrm{mL}$ ) e expressos como $\mathrm{mg}$ de EAG (equivalentes de ácido gálico) por g de extrato. 


\section{RESULTADOS E DISCUSSÕES}

Os extratos em etanol das partes do fruto maduro (polpa, casca e sementes) obtiveram rendimentos respectivamente iguais a 5,3\%; $5,9 \%$ e 3,3\%. Já os extratos do fruto verde da polpa, casca e sementes do noni apresentaram rendimentos $6,0 \% ; 8,8 \%$ e $6,0 \%$, respectivamente. Pode-se observar que o rendimento dos extratos foram superiores quando se trata do fruto verde da polpa.

Para a determinação do teor de fenóis foi realizado o método de Folin-Ciocalteau e os resultados expressos em equivalência de ácido gálico (EAG) por grama de extrato bruto. Os valores podem ser observados na Tabela 1.

Tabela 1 - Teor de fenóis totais obtido pelo método Folin-Ciocalteau dos extratos da Morinda citrifolia Linn

\begin{tabular}{c|c}
\hline MATERIAL VEGETAL & FENÓIS TOTAIS (mg EAG/g de extrato bruto) \\
\hline EEPNV & 63,9 \\
EECNV & 181,0 \\
EESNV & 160,0 \\
EEPNM & 18,3 \\
EECNM & 41,1 \\
EESNM & 41,1 \\
\hline
\end{tabular}

EEPNV: Extrato etanólico da polpa do noni verde (Morinda citrifolia $L$ )

EECNV: Extrato etanólico das cascas do noni verde ( Morinda citrifolia L)

EESNV: Extrato etanólico da semente do noni verde ( Morinda citrifolia L)

EEPNM: Extrato etanólico da polpa do noni maduro ( Morinda citrifolia $L$ )

EECNM: Extrato etanólico das cascas do noni maduro ( Morinda citrifolia $L$ )

EESNM: Extrato etanólico da semente do noni maduro ( Morinda citrifolia $L$ )

Os extratos que apresentaram uma maior concentração de fenóis foram os extratos da casca e das sementes do fruto verde, sendo respectivamente iguais a 181,0 e $160,0 \mathrm{EAG} / \mathrm{g}$ de extrato bruto. Vale ainda ressaltar que todas as partes estudadas ( polpa, casca e semente) os valores foram superiores quando analisados do material verde. $O$ trabalho foi comparado com o de Costa et al. (2013), esses resultados podem ser observados na Tabela 2.

TABELA 2 - Teores de fenólicos totais (expresso em equivalente de ácido gálico) presente no extrato etanólico da polpa, da casca e da semente do Noni (Morinda citrifolia Linn.)

\begin{tabular}{c|c|c|c}
\hline Extratos & \multicolumn{3}{c}{ *Teores de fenólicos totais (mg/100 g de amostra) } \\
\hline & Polpa & Casca & semente \\
\hline Etanólico & $20,33 \pm 1,37 \mathrm{~b}$ & $18,82 \pm 1,26 \mathrm{~b}$ & $11,22 \pm 1,63 \mathrm{~b}$ \\
\hline
\end{tabular}

Analisando a Tabela 2, é possível observar que os resultados obtidos foram satisfatórios para fenóis. Para Chan-Blanco et al. (2006) os compostos bioativos mais abundantes no noni são os fenólicos, sendo que estes relacionados com sua atividade antioxidante. 


\section{CONCLUSÃO}

Através do estudo do noni, pode-se observar que os resultados para esta espécie foram bastante promissores, devido o mesmo ter apresentado elevados teores de fenóis, e estes estão diretamente relacionados à capacidade antioxidante, demonstrando assim a importância de se estudar a Morinda citrifolia Linn, e confirmar seu amplo uso na medicina popular.

\section{AGRADECIMENTOS}

Os autores agradecem ao Instituto Federal de Educação, Ciência e Tecnologia do Rio Grande do Norte - IFRN, Campus Apodi pela disponibilização do espaço cedido e ao Conselho Nacional de Desenvolvimento Científico e Tecnológico (CNPq) pelas bolsas concedidas e apoio financeiro para realização do projeto.

\section{REFERÊNCIAS}

BONOLI, M.; VERARDO, V.; MARCONI, E.; CABONI, M. F Antioxidant Phenols in Barley (HordeumvulgareL.) Flour: Comparative Spectrophotometric Study Among Extraction Methods of Free and Bound Phenolic Compounds. Journal of Agricultural and Food Chemistry. v. 52, p. 5195-5200, 2004.

CHAN-BLANCO, Y.; VAILLAN, F.; PEREZ, A. M.; REYNES, M.; BRILLOUET, J.; BRAT, P. The noni fruit (Morinda citrifolia L.): A review of agricultural research, nutritional and therapeutic properties. Journal of Food Composition and Analysis, v.19, p.645-654, 2006.

COSTA, A. B.; DE OLIVEIRA, A. M. C.; SILVA, A. M. O; MANCINI-FILHO, J.; DE LIMA, A . Atividade antioxidante da polpa, casca e sementes do noni (Morinda citrifolia linn). Revista Brasileira de Fruticultura, Jaboticabal - SP, v. 35, n. 2, p. 345-354, 2013.

COSTA, A. B. Atividade antioxidante in vitro e antifungicida do noni (Moringa citrifolia L.). Dissertação de Mestrado. Universidade Federal do Piauí. Programa de Pós-Graduação em Alimentos e Nutrição. Teresina, 2001.

HEINICKE, R. M. The pharmacologically active ingredient of noni. Pacific Tropical Botanical Garden Bulletin. v. 15, p. 10-14. 1985

KAMIYA, K.; HAMABE, W.; HARADA, S.; MURAKAMI, R.; TOKUYAMA, S.; SATAKE,T. Chemical constituents of Morinda citrifolia roots exhibit hypoglycemic effects in streptozotocin- induced diabetic mice. Biological and Pharmaceutical Bulletin, v. 31, n. 5, p.935-938, 2008. 